\title{
Analysis of the Cleburne, Texas, Earthquake Sequence from June 2009 to June 2010
}

\author{
by Ashley Howe Justinic, Brian Stump, Chris Hayward, and Cliff Frohlich
}

\begin{abstract}
On 9 June 2009, an $M_{\mathrm{bLg}} 2.8$ earthquake shook Cleburne, Texas, a community not known to have previously experienced earthquakes. Over 50 small earthquakes followed by the end of December 2009. A temporary network of four and then five IRIS-Passcal broadband systems was deployed from June 2009 to June 2010, recording data that were used to locate 38 events with the most confident $P$ - and $S$-arrival picks. Event locations were distributed along a $2 \mathrm{~km}$ long north-northeast trend. The location centroid was at $32.298^{\circ} \mathrm{N}, 97.372^{\circ} \mathrm{W}$ and at $3.6 \mathrm{~km}$ depth. This location is approximately $1.3 \mathrm{~km}$ from a saltwater disposal well that began injection in October 2007 and $3.2 \mathrm{~km}$ away from a second injection well that was active from September 2005 to late July 2009. Focal mechanisms estimated for the best-recorded events suggest a north-northeast-south-southwest-trending normal fault with a dip of $\sim 50^{\circ}$ and a component of oblique motion (rake of $\sim-80^{\circ}$ ). This average solution is generally consistent with the north-northeast-trending extensional faults that are prevalent across parts of Texas, Oklahoma, Louisiana, and Arkansas. Stress drops calculated from $P$ and $S$ spectra for seven different events ranged from 3.9 to 90 bars, with most estimates between 40 and 50 bars, typical values for intraplate earthquakes. Because there were no known previous earthquakes, and the located events were close to the two injection wells and near the injection depth, the possibility exists that earthquakes may be related to fluid injection.
\end{abstract}

Online Material: Tables of absolute and relative earthquake locations and a figure summarizing focal mechanism solutions.

\section{Introduction}

On 2 June 2009, a series of earthquakes began near Cleburne, Texas, an industrial city of 30,300 located in Johnson County, about $50 \mathrm{~km}$ south of Fort Worth. This area had no known history of seismicity and no known active faults. The largest event observed had a magnitude $M_{\mathrm{b} L g}$ of 2.8 , and there were numerous smaller events continuing at least through December 2010, some of which were felt locally. Based on felt reports from the 2 June events, a network of four and then five broadband seismometers was deployed around Cleburne and then modified as further activity was recorded. Fifty-four earthquakes were detected during the time when the instruments were present between June 2009 and June 2010.

By November 2010 the U.S. Geological Survey (USGS)'s National Earthquake Information Center (NEIC) had reported nine more events with $M_{\mathrm{b} L g}$ between 2.0 and 2.8 and depths fixed at $5 \mathrm{~km}$ because of insufficient seismic station coverage above the hypocenter. The NEIC revised magnitude estimates from February 2012 are used in this paper.
A large portion of the Fort Worth basin, including Cleburne, Texas, is underlain by the Barnett Shale, a Mississippian age unconventional gas reservoir that was discovered in 1981 (Martineau, 2007). Productive wells are located in 23 counties, including Johnson County where the earthquakes in this study occurred. As of 25 February 2010, there were 13,740 gas wells run by 246 operators. In 2009 , there were a total of 136 injection wells and commercial saltwater disposal wells. Gas well production in the Barnett Shale totaled 1764 Bcf, or $26 \%$ of Texas production (Railroad Commission of Texas, 2009) for 2009. Previous investigations of recent seismicity in the Fort Worth basin have identified numerous small earthquakes occurring in close association with injection wells. The survey in Frohlich (2012) of 67 small earthquakes in the Fort Worth basin from 2009 to 2012 found that all the most reliably located events occurred in eight groups each situated within $3.2 \mathrm{~km}$ of active injection wells. During the study period, other seismic events (Fig. 1) occurred $65 \mathrm{~km}$ to the northeast of Cleburne, near the Dallas/Fort Worth (DFW) airport (Frohlich et al., 2011). 


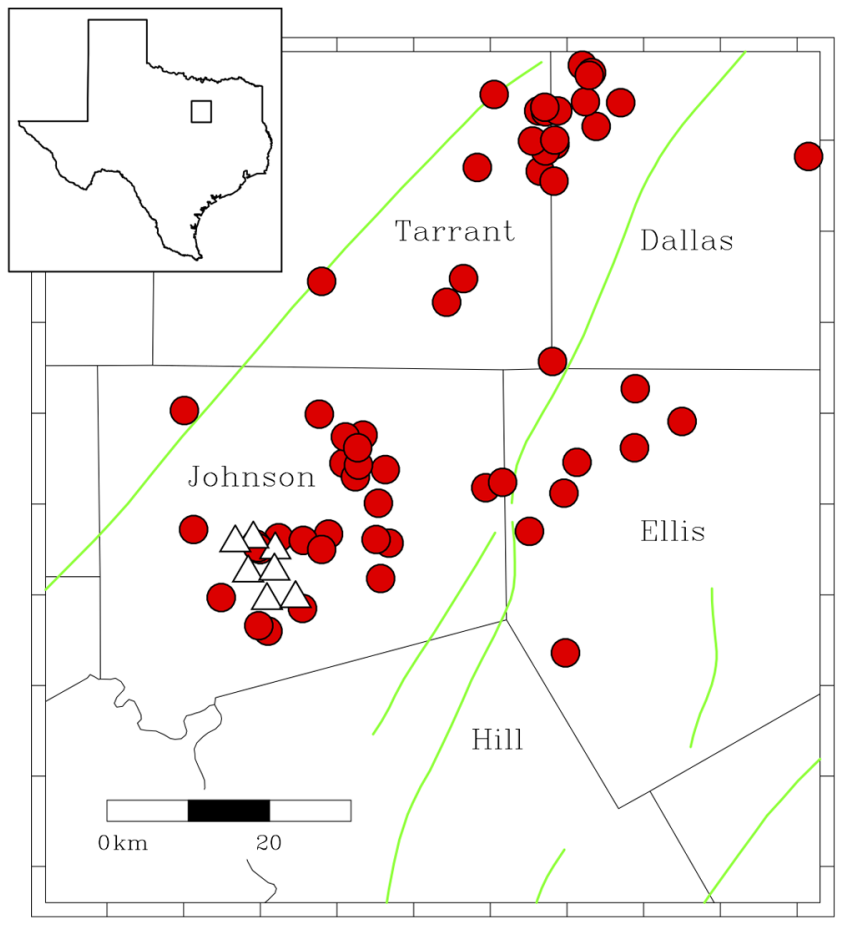

Figure 1 NEIC-observed earthquakes in the region of the study. Earthquake locations are plotted as circles, with triangles as the locations of temporary seismic stations. The mostly diagonal lines are faults as mapped by Ewing (1990). The NEIC reported no earthquakes in this region before 31 October 2008. The color version of this figure is available only in the electronic edition.

The present study not only investigates the Cleburne seismicity, but also its possible relationship to nearby injection wells. Two saltwater disposal wells are situated within a few kilometers of our preferred locations for the Cleburne earthquakes. The first saltwater disposal well (API 42251-30299) commenced injection in September 2005 (Fig. 2). The well depth is $3338 \mathrm{~m}$ and perforated between 3177 and $3278 \mathrm{~m}$ (Railroad Commission of Texas, 2007a). It was $3.2 \mathrm{~km}$ from the average Cleburne earthquake location. Injection stopped on 31 July 2009 and in October 2009, four months after the first felt event, the well was voluntarily shutin. A seismometer (CLEI2, Table 1) was installed at this site in December 2009, producing data used in the subsequent location estimates. A second saltwater disposal well (API 42-251-31266) is $1.3 \mathrm{~km}$ from the average earthquake loca-
Injection Volumes by Well

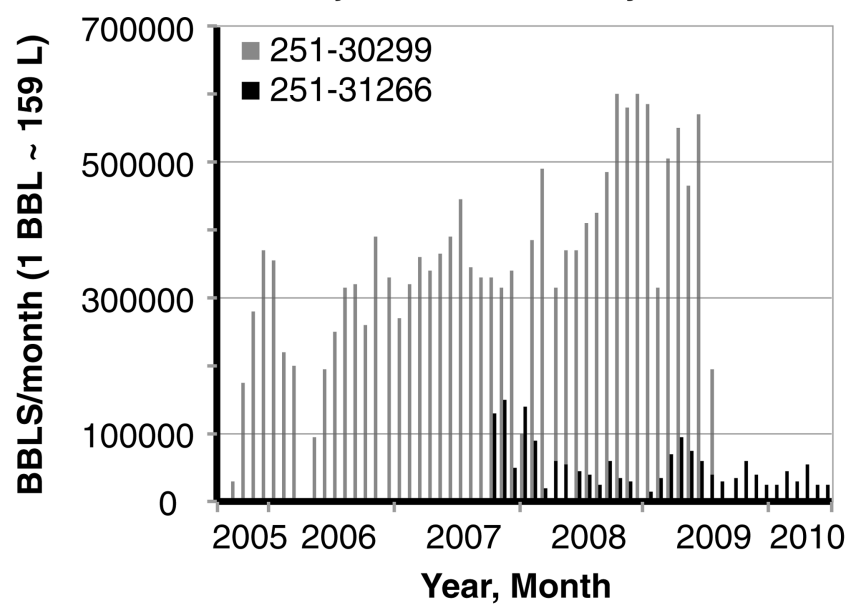

Figure 2. Monthly saltwater injection volumes in units of barrels (BBLS) at two disposal wells near Cleburne. The highest injection volumes were at well API 42-251-30299, situated $3.2 \mathrm{~km}$ north of the average Cleburne epicenter; injection began in September 2005 and continued through July 2009 when it was shut-in. The south well (API 42-251-31266) was $1.3 \mathrm{~km}$ from the average epicenter where injection began in October 2007 and continued until the end of the monitoring.

tion and began injection in August 2007 (Fig. 2). It has a depth of $3087 \mathrm{~m}$ and is perforated from 2397 to $3087 \mathrm{~m}$ (Railroad Commission of Texas, 2007b).

\section{Data and Methods}

\section{Instrument Deployment}

Beginning on 15 June 2009, Southern Methodist University (SMU) scientists deployed a local network of four PASSCAL supplied Quanterra Q330 digitizers and Güralp CMG-40T force feedback broadband seismometers sampling at 200 samples/s. The initial network sites were chosen based on felt reports and had an aperture less than $10 \mathrm{~km}$ (Fig. 1, Table 1). Compared with an earlier study in the DFW area, the Cleburne sites were relatively quiet, yet subject to some anthropogenic noise because they were near or around the city of Cleburne. Preliminary earthquake locations based on data from these instruments indicated that the seismic activity was occurring south of the network, so one

Table 1

Deployment Schedule for the SMU Network

\begin{tabular}{lcccc}
\hline & Latitude $\left(^{\circ}\right)$ & Longitude $\left(^{\circ}\right)$ & Data Start $(\mathrm{yyyy} / \mathrm{mm} / \mathrm{dd})$ & Data Stop $(\mathrm{yyyy} / \mathrm{mm} / \mathrm{dd})$ \\
\hline CLEF1 & N 32.3495 & W 97.3784 & $2009 / 06 / 15$ & $2010 / 06 / 04$ \\
CLEF2 & N 32.3243 & W 97.4157 & $2009 / 06 / 18$ & $2009 / 06 / 04$ \\
CLEF3 & N 32.3616 & W 97.4091 & $2009 / 06 / 18$ & $2009 / 07 / 15$ \\
CLEA1 & N 32.3572 & W 97.4323 & $2009 / 06 / 18$ & $2009 / 11 / 24$ \\
CLERV & N 32.2938 & W 97.3913 & $2009 / 07 / 15$ & $2009 / 12 / 18$ \\
CLELK & N 32.2960 & W 97.3540 & $2009 / 08 / 04$ & $2010 / 06 / 04$ \\
CLEI2 & N 32.3263 & W 97.3816 & $2009 / 10 / 01$ & $2010 / 01 / 12$ \\
& & & & \\
\hline
\end{tabular}




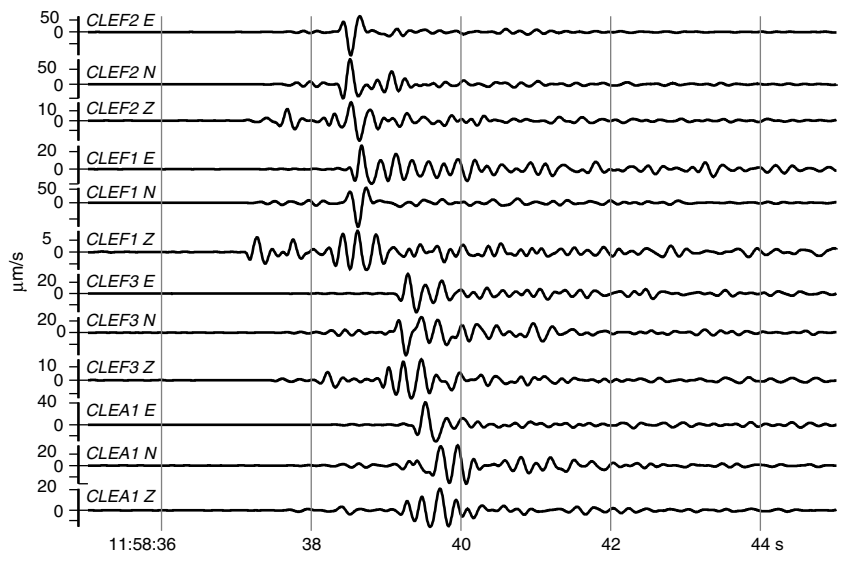

Figure 3. A typical earthquake (Julian date 20091911158) as recorded on the local network with the initial configuration of four stations. Data are filtered, $1-5 \mathrm{~Hz}$. This event was reported by the NEIC as a magnitude $M_{\mathrm{b} L g} 2.0$.

of the stations (CLEF3) was relocated to station CLERV south of the city, and another seismometer (CLELK) was added later (Table 1). Station CLEI2 was added on 1 October 2009 at the site of the shut-in injector (API 42-251-30299).

\section{Data Examples}

Data were filtered between 1 and $5 \mathrm{~Hz}$ (Fig. 3) to focus on the frequency band with the maximum signal-to-noise level for event detection. Noise levels were especially low early in the deployment period. In addition to local earthquakes, the network also recorded signals from nearby quarry blasts. These events were distinguishable from earthquakes as they have strong, short-period surface waves arriving on the vertical channel after the $S$-wave arrival. Over 200 quarry blasts were detected on the network during the monitoring period based on these $R g$ criteria (Goforth and Bonner, 1995).

\section{Locations}

Event hypocenter estimates were determined from $P$ and $S$-arrival times (Fig. 3) using a standard weighted leastsquares approach (Frohlich, 1993). Each travel-time residual was weighted by a user-assigned quality factor based on signal-to-noise ratio and waveform character. Arrival times were measured and reported to the nearest sample point $(1 / 200 \mathrm{~s})$. Of the 54 detected events, locations were calculated for the 38 best-recorded events. The signal-to-noise ratio averaged about 40 in the $1-5 \mathrm{~Hz}$ frequency band.

The initial velocity model used for event location was based on a well report by The Geotechnical Corporation (1964) for the Trigg No. 1 well in Dallas County. Although the well location is over $60 \mathrm{~km}$ to the north of Cleburne, the crustal structures at the two locations in the Fort Worth basin are similar and provide a starting place for the investigation. The 1D velocity model developed from the Trigg No. 1 consisted of a single layer over a half-space. The $P$ velocity in the $2.37 \mathrm{~km}$ thick surface layer was $3.54 \mathrm{~km} / \mathrm{s}$ and $5.85 \mathrm{~km} / \mathrm{s}$ in the half-space, with a $V_{P} / V_{S}$ ratio of 1.8 . The surface layer is primarily Pennsylvanian, and the half-space represents the Ordovician Ellenburger formation.

Based on proprietary data from the Cleburne area, a $500 \mathrm{~m}$ low-velocity surface layer $\left(V_{P}=2.75 \mathrm{~km} / \mathrm{s}\right)$ was added. Locations using this second model (Fig. 4) moved about $300 \mathrm{~m}$ to the northwest and $310 \mathrm{~m}$ upward from those estimated using the initial velocity model. (E) A full listing of these locations is found in Table S1 in the electronic supplement to this article.

Estimated event locations are slightly spatially scattered despite the similarity of waveforms partly due to the changing station configuration over time. Events farthest to the north (shown by plus symbols in Fig. 4) had the poorest station coverage, reflecting the initial station distribution, and the largest azimuthal gap. As stations were added or moved to surround the events, the epicentral locations moved southward; however, there is overlap among events detected with early and late station configurations. The mean event epicenter, using all network configurations, was $32.298^{\circ} \mathrm{N}$, $97.372^{\circ} \mathrm{W}$. This is 1.3 and $3.2 \mathrm{~km}$, respectively, from the two injection wells. The average formal standard error is $0.04 \mathrm{~km}$ but does not account for errors introduced by the assumed 1D velocity model. Depths ranged from 1.62 to $4.97 \mathrm{~km}$ with an average of $3.55 \mathrm{~km}$.

To better assess the spatial distribution of the activity, locations for 21 events were also calculated relative to a well-located master event at $32.293^{\circ} \mathrm{N}, 97.372^{\circ} \mathrm{W}$ with a depth of $3.85 \mathrm{~km}$ (Fig. 5). (E) A full listing of these relative locations is given in Table S2 in the electronic supplement. Stations CLEF1, CLERV, and CLELK were used for the relative relocations based on their good station geometry. This method assumes that travel-time residuals are a result of relative changes between the source and receiver locations. Therefore, if events originate from a common area, the travel-time model and residuals will be similar from event to event (Havskov and Ottemoller, 2010), and the residuals for the master event may be treated as station corrections. As with the previous locations, the relative locations for the Cleburne events (Fig. 5) show no tendency to migrate over time. Events occurred along a roughly linear north-south trend within an approximately $300 \mathrm{~m}$ thick zone centered at a depth of about $3.85 \mathrm{~km}$. Assuming that these locations are accurate and that they occur a dipping fault approximately $45^{\circ}$ to the east or west, the dimensions of the fault surface would be $450 \mathrm{~m}$ by $1500 \mathrm{~m}$ with an estimated fault area of $0.68 \mathrm{~km}^{2}$.

\section{Earthquake Size}

There is no accepted local magnitude scale for earthquakes in this part of Texas. For this study, we determined the relative source size using the logarithm of the amplitude of the earthquake signal recorded on the HHE component of station CLEF1 (Fig. 6) because this station spanned the total duration of the deployment and produced signals with good 


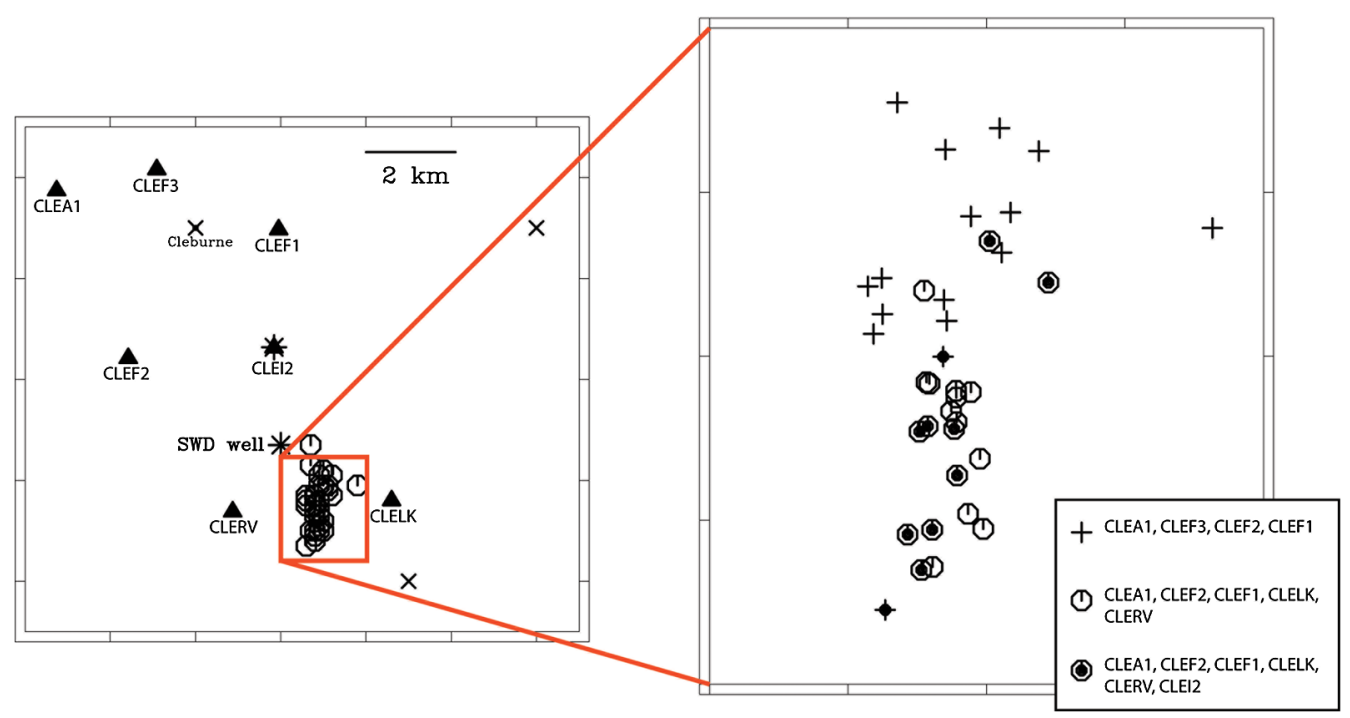

Figure 4. Final event locations determined from data recorded by the local network. Triangles are seismic stations; plus symbols, octagons; circles, earthquakes; and asterisks, injection disposal wells. Events located using data from the initial four stations (plus symbols) are more northward. Events locations using the final network configuration (circles) should be more reliable because stations surrounded the events. Note that locations form an approximate north-south trend about $2 \mathrm{~km}$ long, with a saltwater disposal well (API 42-251-31266) situated about $1.3 \mathrm{~km}$ from the trend.

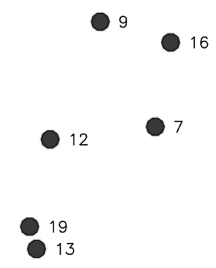

(a)

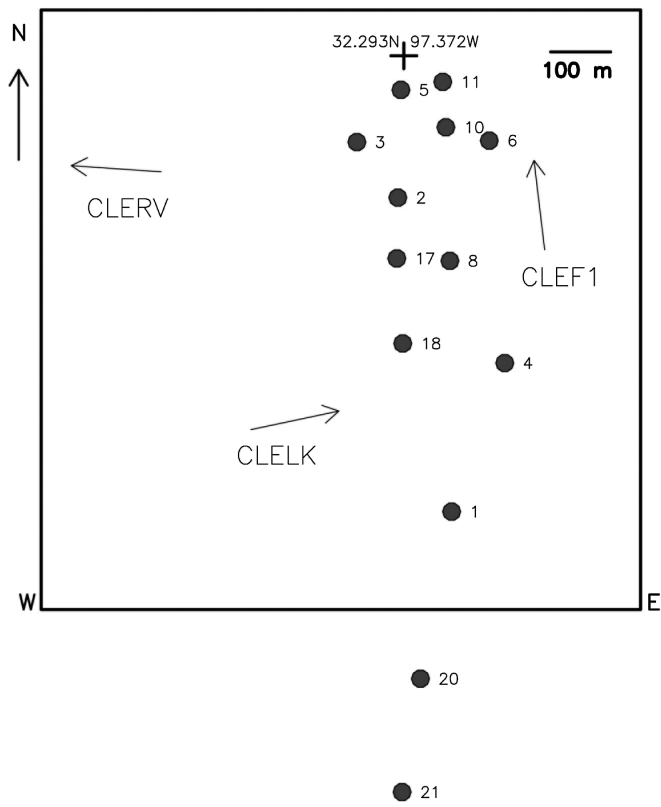

(b)

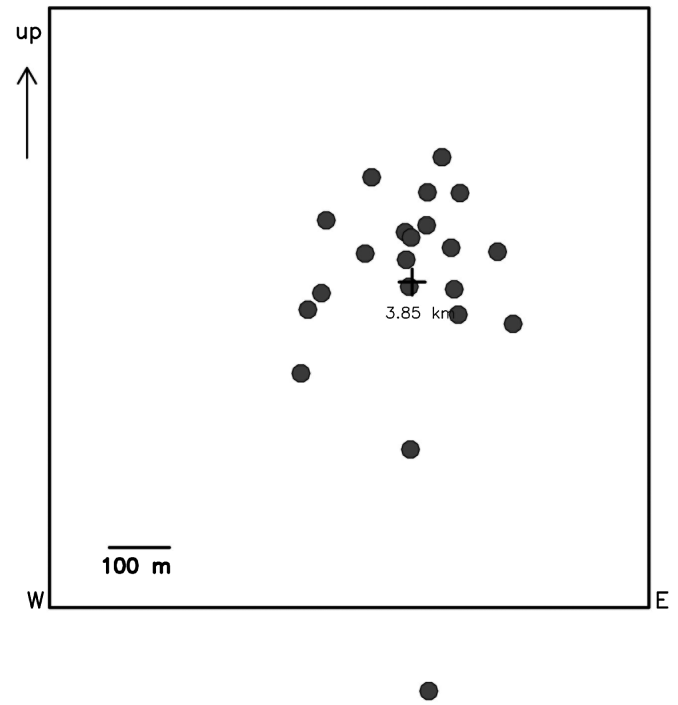

Figure 5. Relative locations for 21 events (circles) with respect to a master event at $32.293^{\circ} \mathrm{N}, 97.372^{\circ} \mathrm{W}$ (plus symbol) at a depth of $3.85 \mathrm{~km}$. Each square is $1.0 \mathrm{~km}$ on a side. (a) The map view showing epicenters; locations form a north-south trend. (b) An east-west cross section. A dipping fault would likely produce events across a range of depths, several hundred meters in this case. 


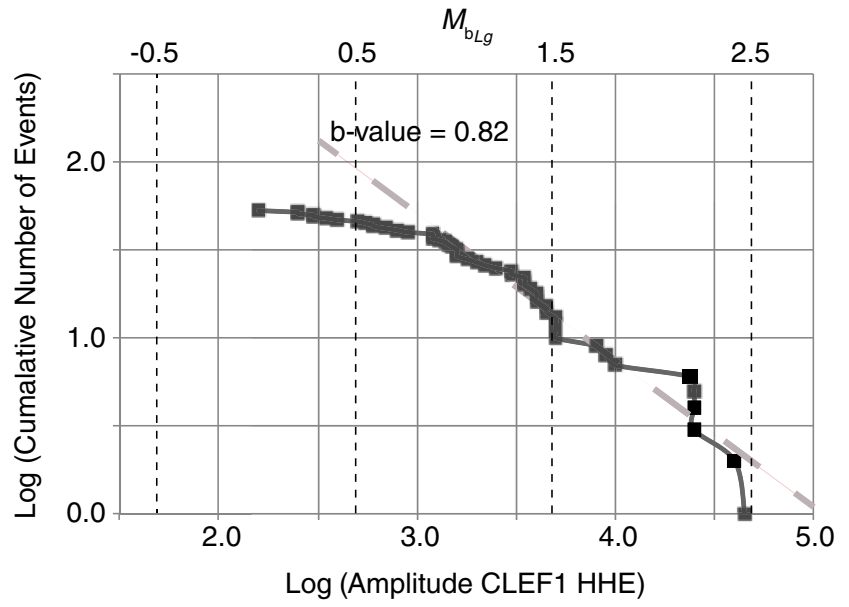

Figure 6. The logarithm of event amplitudes plotted against the logarithm of the cumulative number of events having equal and larger amplitudes. The slope decreases for log amplitudes of $\sim 3.00$ and smaller, suggesting that some small-magnitude events are not detected. A $b$-value of 0.82 was calculated using $\sim 3.00$ as the threshold amplitude. This $b$-value is represented by the dashed line. The magnitude scale along the top axis is relative and is based on NEIC-determined magnitudes that were available for the four events in bold. The color version of this figure is available only in the electronic edition.

signal to noise (Fig. 3). $S-P$ times were similar for all the detected events at this station consistent with the same source to station distance for all events.

This relative scale was subsequently calibrated against $M_{\mathrm{b} L g}$ using the four events that were assigned regional magnitudes by the NEIC. In order to estimate the relative distribution of earthquakes as a function of magnitude, the log of the cumulative number of events at a given log amplitude or greater is plotted against the log amplitude at CLEF1 with the $M_{L g G S}$ calibration shown. This result suggests that event magnitudes detected by the local array range from approximately $M_{\mathrm{b} L g} 0.0$ to 2.5 . The largest Cleburne earthquake, an $M_{\mathrm{b} L g} 2.8$, preceded deployment of the local network. Aki's method (Aki, 1965) was used to estimate the $b$-value for these data. Log amplitudes were used instead of magnitudes because a local magnitude scale was not absolutely constrained.

$$
b=\frac{1}{\ln (10)}\left(M_{\text {Thresh }}-\bar{M}_{\mathrm{All}}\right) .
$$

A threshold log amplitude of $3.08\left(\sim M_{\mathrm{b} L g}=0.9\right)$ was chosen as the data suggest that events below this threshold may not be completely sampled based on the decrease in the slope of the Gutenberg-Richter plot (Fig. 6). The mean log amplitude of all events greater than or equal to the threshold was $3.61\left(\sim M_{\mathrm{b} L g} \leq 1.4\right)$. A $b$-value of 0.82 was estimated from the observations.

\section{Focal Mechanisms}

Focal plane solutions for the Cleburne earthquakes were calculated using the program FOCMEC (Snoke, 2009) which
CLEEF3

CLEF1
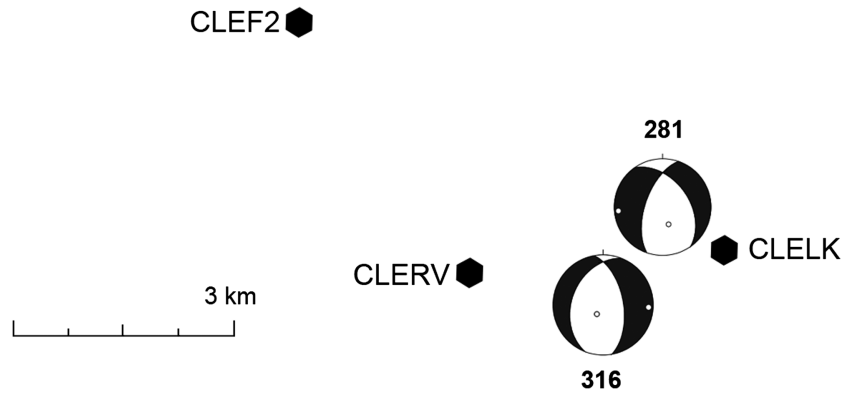

Figure 7. Two characteristic focal mechanisms for events 281 and 316 are shown relative to the station distribution. (E) A summary of all the focal solutions found in this study is given in Figure S1 in the electronic supplement to this article.

calculates the range of possible double-couple earthquake focal mechanisms consistent with $P, S V$, or $S H$ polarities and/or amplitude ratios $(S V / P, S H / P, S V / S H)$ (Kisslinger, 1980). FOCMEC was developed for local to regional events for which determining moment tensors from waveform modeling may be difficult.

Five of the well-recorded and better-located earthquakes, all having magnitudes smaller than 2.0, were chosen for fault plane estimation (Fig. 7 and (E) Table S1 available in electronic supplement). These events encompass three different seismic network configurations. Event 189 (numbered by Julian day) had data from stations CLEA1, CLEF1, CLEF2, and CLEF3; event 201 from CLEA1, CLEF1, CLEF2, and CLERV; and events 253, 281, and 316 from stations CLEA1, CLEF2, CLEF2, CLERV, and CLELK. Horizontalcomponent seismograms were rotated into radial $(S V)$ and transverse $(\mathrm{SH})$ components for determining polarities and amplitudes ratios. The $S H / P$ ratio was used because the $S V$ peaks and troughs were harder to identify. Snoke (2009) notes that any amplitude ratio can be calculated from one of the other two, because they are dependent on one another.

Three of the events $(201,281$, and 316$)$ produced bestfitting focal mechanisms that were relatively unambiguous. The two events that were most consistent, 281 and 316, produced predominantly normal-faulting mechanisms with one north-northeast-south-southwest plane as illustrated in Figure 7. Focal plane estimates for event 201 produced a predominantly strike-slip mechanism with one northeastsouthwest-trending nodal plane. For events 253 and 189, there was ambiguity in the solutions as two dissimilar families of mechanisms fit the data. (E) The complete distribution of fault plane solutions for all the events is summarized in Figure S1 found in the electronic supplement. Strikes 
between $0^{\circ}$ and $90^{\circ}$ (northeast) and between $180^{\circ}$ and $225^{\circ}$ (south-southwest) predominate. Strikes $180^{\circ}$ apart are unique solutions because the convention is for the strike direction to be toward the left when facing downdip. Dips from $40^{\circ}$ to $60^{\circ}$ predominate. Rakes between 90 and 50 are most common. A negative rake indicates a normal (extensional) fault. A negative rake other than 90 suggests an oblique component of fault motion. Thus both the two best solutions in Figure 7 and the overall distribution of solutions in (E) Figure S1 (available in the electronic supplement to this article) are consistent with the strike of the fault estimated from the locations and the regional stress field.

\section{Kinematic Source Parameters}

Kinematic source parameters describe an earthquake in terms of its intrinsic characteristics such as scalar moment $M_{0}$, fault slip $S$, fault area $A$, stress drop $\Delta \sigma$, and seismic energy $E_{0}$, often based on the Brune model (Brune, 1970).

$$
S(f)=\frac{F M_{0}}{\left[1+\left(f / f_{\mathrm{c}}\right)^{2}\right] 4 \pi \rho c^{2} R} .
$$

In this representation, $S(f)$ is the displacement spectra, $f_{\mathrm{c}}$ is the source corner frequency, and $c$ and $\rho$ are the velocity and density at the source, respectively, $R$ is the sourcestation distance, and $F$ is a double-couple radiation coefficient. At low frequencies the displacement spectrum is flat, that is, $S(0)=\Omega_{0}$ a constant; at high frequencies, the spectrum decays as $f^{2}$.

This component of the analysis estimated source parameters for seven earthquakes (see (E) Table S1, available in electronic supplement) in the time domain using the method of Urbancic et al. (1996). This method relies on calculating the integral of the squared velocity time history $\left(S_{V 2}\right)$ and the squared displacement time history $\left(S_{D 2}\right)$ from $P$ and $S$ waves. Trifu et al. (2000) corrected the original equations for $S_{V 2}$ and $S_{D 2}$, which had an extraneous coefficient of two outside the integral. The correct equations are

$$
S_{D 2}=\int_{0}^{\infty} D^{2}(t) d t,
$$

and

$$
S_{V 2}=\int_{0}^{\infty} V^{2}(t) d t .
$$

$S_{V 2}$ and $S_{D 2}$ can be estimated from the $P, S V$, and $S H$ wave trains at each of the five recording stations; thus, for some events there were 15 separate estimates for each source parameter. The $P$-wave train was analyzed on the vertical channel and extended from the $P$ first motion to the onset of the $S$ wave. For analysis of $S$, east and north seismograms were rotated into $S V$ and $S H$, with $S$-wave trains starting at the onset of $S$ and extending to twice the $S$-wave travel time.
The Urbancic et al. (1996) expressions for $\Omega_{0}$, corner frequency $f_{\mathrm{c}}$, and energy flux $J$ in terms of $S_{V 2}$ and $S_{D 2}$ are

$$
\begin{aligned}
& \Omega_{0}=\sqrt{4 S_{D 2}^{3 / 2} S_{V 2}^{-1 / 2}}, \\
& f_{\mathrm{c}}=\frac{1}{2 \pi} \sqrt{S_{V 2} / S_{D 2}},
\end{aligned}
$$

and

$$
J=S_{V 2}
$$

From these parameters one can calculate scalar moment $M_{0}$, energy $E_{0}$, source radius $r_{0}$, and stress drop $\Delta \sigma$ :

$$
M_{0}=\frac{4 \pi \rho c^{3} R \Omega_{0}}{F},
$$

$$
E_{0}=4 \pi \rho c^{3} R^{2} J,
$$

$$
r_{0}=\frac{K c_{S}}{2 \pi f_{\mathrm{c}}},
$$

and

$$
\Delta \sigma=\frac{7 M_{0}}{16 r_{0}^{3}} .
$$

The double-couple radiation coefficient, $F$, was taken as 0.52 for $P$ waves and 0.63 for $S$ (Boore and Boatwright, 1984). The density $\rho$ was $2.68 \mathrm{~g} / \mathrm{cm}^{3}$ based on Trigg Well No. 1 data (Geotechnical Corporation, 1964). The source velocities $c_{P}$ and $c_{S}$ used were those of the half-space in our velocity model with a $P$ velocity of $5.85 \mathrm{~km} / \mathrm{s}$ and a $P$-to- $S$ velocity ratio of $1.8 . K$ is a constant, 2.01 for $P$ and 1.32 for $S$. Note that $r_{0}$ is cubed in the equation for stress drop, so errors in corner frequency $f_{\mathrm{c}}$ and hence $r_{0}$ greatly affect estimates of stress drop $\Delta \sigma$. Fortunately, for individual earthquakes, the ratios of $S_{V 2}$ to $S_{D 2}$ were not highly variable when determined using data from $P, S H$, or $S V$ at the different stations.

Mean estimates for $f_{c}$ ranged between 3 and $18 \mathrm{~Hz}$, well within the frequency band with good frequency-to-noise ratios. Corner frequency estimates based on $P$ were noticeably larger $(7-26 \mathrm{~Hz})$ than those based on $S V$ and $S H(1.2-$ $9.3 \mathrm{~Hz}$ ), because the corner frequency reflects the source dimension as coupled through the appropriate $S$ - or $P$-wave velocity (Table 2 ).

Mean estimates for moment $M_{0}(P, S V, S H$ combined $)$ were between $2.0 \times 10^{19}$ and $2.7 \times 10^{20} \mathrm{dyn} \cdot \mathrm{cm}$ for the seven events (Fig. 8a). The variance in the moment estimates does not appear to correlate with $M_{0}$, nor were there significant differences in $M_{0}$ as determined from $P, S V$, and $S H$ signals. The estimates of source radius $r_{0}$ ranged from 39 

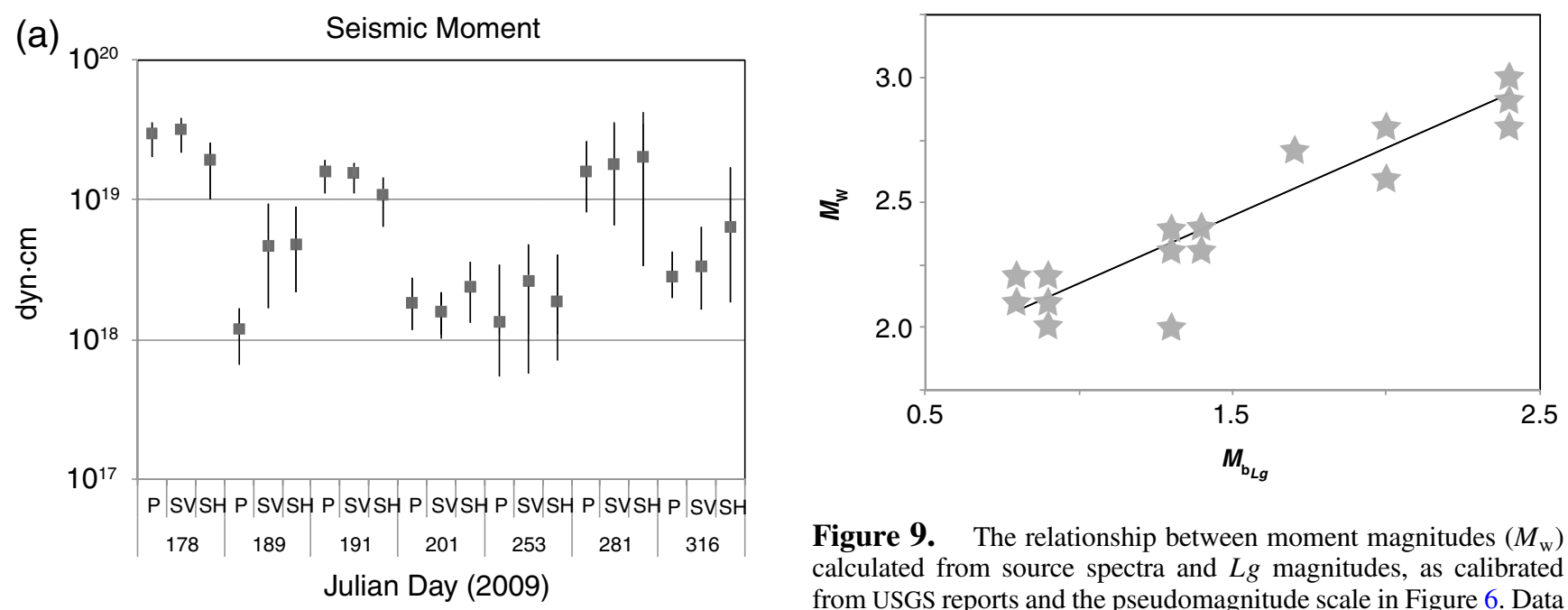

Figure 9. The relationship between moment magnitudes $\left(M_{\mathrm{w}}\right)$ calculated from source spectra and $L g$ magnitudes, as calibrated from USGS reports and the pseudomagnitude scale in Figure 6. Data points are based on average $P, S V$, and $S H$ estimates for $M_{\mathrm{w}}$ across all stations.

$$
M_{\mathrm{w}}=\frac{2}{3} \log M_{0}-10.7
$$

and compared these (Fig. 9) with the $M_{\mathrm{bLg}}$ magnitudes, as calibrated from USGS reports and the pseudomagnitude scale (Fig. 6) that we developed. The best-fitting relationship was

$$
M_{\mathrm{w}}=0.5 M_{\mathrm{b} L g}+1.6 .
$$

\section{Discussion}

The lack of previous felt seismicity in the Cleburne area,

Figure 8. (a,b) The mean seismic moment and stress drop estimates for a specific wave type and event are shown as squares. The bars are \pm one standard deviation. Event 178 (20091780330) has an $M_{\mathrm{b} L g} 2.4$ and event 191 (20091911158) has an $M_{\mathrm{b} L g} 2.0$.

to $563 \mathrm{~m}$ with most estimates between 75 and $200 \mathrm{~m}$. Average estimates of stress drop $\Delta \sigma(P, S V, S H$ combined $)$ ranged between $5.5 \times 10^{5}$ and $128 \times 10^{8} \mathrm{dyn} \cdot \mathrm{cm}^{-2}$, or 5.5 and 128 bars (Fig. 8b), with the overall average for all estimates of 43.4 bars, in accord with estimates for intraplate earthquakes (Kanamori and Anderson, 1975).

We calculated moment magnitudes $M_{\mathrm{w}}$ based on the relation the active recovery of natural gas in the area associated with the Barnett Shale, and the nearby location of wastewater injection wells motivated an investigation of these earthquakes and their characteristics in order to assess if there was any relationship to human activities. In the case of the nearby earthquakes at DFW airport, a plausible linkage was found between the disposal of the wastewater and the subsequent earthquakes in the region (Frohlich et al., 2011). A more comprehensive study of local seismicity throughout the Fort Worth basin (Frohlich, 2012) using USArray data to detect and locate events across the basin concludes that there may be a number of locations where small earthquakes are occurring near wastewater injectors. As a result of these previous

Table 2

\begin{tabular}{|c|c|c|c|c|c|c|}
\hline & \multicolumn{3}{|c|}{ Source Radius (m) } & \multicolumn{3}{|c|}{ Corner Frequency (Hz) } \\
\hline & $P$ & $S V$ (Radial) & $S H$ (Transverse) & $P$ & $S V$ (Radial) & SH (Transverse) \\
\hline CLEA1 & 132 & 109 & 164 & 8 & 6 & 4 \\
\hline CLEF1 & 77 & 120 & 90 & 14 & 6 & 8 \\
\hline CLEF2 & 118 & 113 & 127 & 9 & 6 & 5 \\
\hline CLEF3 & 116 & 137 & 104 & 9 & 5 & 7 \\
\hline
\end{tabular}

Source Radius and Corner Frequency for Event 191, an $M_{\mathrm{b} L g} 2.0$

BSSA Early Edition 


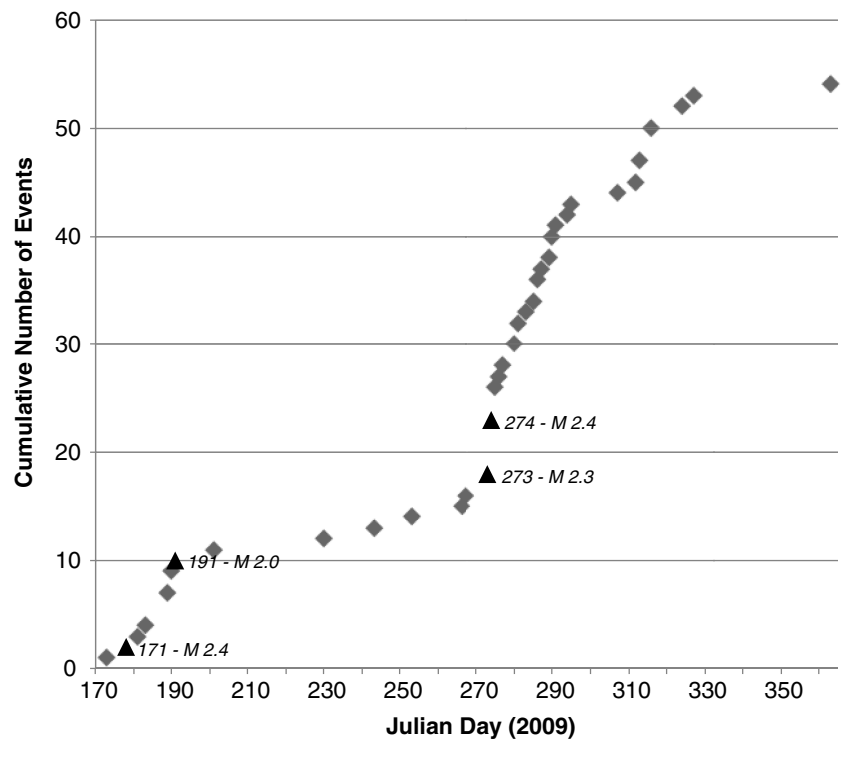

Figure 10. The time sequence of events detected during the deployment of portable instruments around Cleburne. There were 10 events in June and early July 2009, followed by four events in late July, August, and September. Activity increased again in October and November, with a total of 54 by the end of December. No earthquakes were detected between January and June 2010, when the instrumentation was removed.

studies, the details of the Cleburne earthquake sequence are investigated pursuant of a possible relationship to the disposal of fluids at depth (Howe, 2012).

\section{Earthquake Timing}

The temporal distribution of the Cleburne earthquakes was different from that of the DFW earthquakes (Frohlich et al., 2011). The DFW events occurred in rapid bursts, with as many as 30 events in a single day with intervening periods of relative quiescence as long as 30 days. In the Cleburne sequence, by comparison, there were at most five earthquakes in a single day (Fig. 10). Many days had only one earthquake, while intervening weeks had no events. The earthquakes tapered off significantly after December 2009 with no events detected between January 2010 and June 2010 when the SMU network was removed. Subsequently, one additional event was reported by the USGS in November 2010.

\section{Earthquake Size Distribution}

As previously discussed, Aki's method yielded a $b$ value estimate of 0.82 for this sequence. An average $b$-value for tectonic earthquakes is 0.95 with a range from 0.94 to 0.30 (Shi and Bolt, 1982). Earthquake sequences associated with hydrofracture have been found to be enriched in the relative number of small magnitude events as reported by Fehler and Phillips (1991). In their study, $b$-values were estimated as 1.5 using a borehole seismometer and 1.9 with a surface seismometer. These values are much larger than those found for the Cleburne sequence.

\section{Location}

Event locations cluster along a north to north-northeast trend with a total linear extent of approximately $2 \mathrm{~km}$ (Figs. 4 and 5). This linear trend is consistent with the kinematic estimates of fault length for individual events like those documented in Table 2 and may represent the fault on which the earthquakes occurred. The north to north-northeast trend is also comparable with the trend of many known faults in Texas, Oklahoma, and Louisiana (Ewing, 1990) as well as the orientation of current stress field that supports normal faulting motion along faults that trend northeast-southwest (Sullivan et al., 2006; Tingay et al., 2006). Although the orientation of the fault estimated by the locations departs slightly from the mapped faults in the region as documented in Figure 1, the departure is small and may reflect local variations in strike within the region.

The two injection wells that are near these epicenters (Fig. 4) are reported to inject into the Ellenburger limestone. It is possible that as a result of these fluid injections the pore pressure changes may migrate outside of the immediate vicinity of the well to trigger fault slip (Evans, 1966; Herrmann et al., 1981) by changing the effective stress on an existing fault surface. The range of estimated earthquake depths $(1.62-4.97 \mathrm{~km})$ encompasses the injection intervals of both disposal wells (API 42-251-30299, 3.18-3.28 km; API 42-251-31266. 2.40-3.09 km).

It is well known that earthquake locations using local data can depart from those employing regional data, especially in the estimation of source depth. This difference was found in this study as documented with the $M_{\mathrm{b} L g} 2.0$ event on 10 July 2009 where a difference in $7 \mathrm{~km}$ at the surface and $1 \mathrm{~km}$ in depth was found. USGS seismic stations are widely spaced at regional distances and thus subject to larger uncertainty and bias in their locations.

\section{Source Mechanism and Kinematics}

Prior to any calculation of local focal mechanisms, the fault inferred from the Cleburne earthquakes based on an understanding of local geology, faults, and stress regime was believed to be an extensional fault striking approximately northeast-southwest with a dip of $45^{\circ}-60^{\circ}$ (Fig. 1). This estimate is based on the type and trend of faults most prevalent in the area (Sullivan et al., 2006; Tingay et al., 2006) and is close to the observed north to north-northeast trend of earthquake locations in this study. The focal mechanism solutions discussed earlier are consistent with this geologic expectation.

The source parameters calculated for seven of the Cleburne events yielded a quantitative understanding of their size and character. Average seismic-moment estimates for the seven events ( $P, S V$, and $S H$ combined) ranged from $\sim 2.0 \times 10^{19}$ to $\sim 2.7 \times 10^{20} \mathrm{dyn} \cdot \mathrm{cm}$ and corner frequency 
Table 3

Seven Questions to Assess Likelihood Earthquakes are Induced (Davis and Frohlich, 1993)

\begin{tabular}{|c|c|}
\hline Question & $\begin{array}{l}\text { Cleburne } \\
\text { Answer }\end{array}$ \\
\hline $\begin{array}{l}\text { 1. Are the events the first known earthquakes of this } \\
\text { character in the region? }\end{array}$ & Yes \\
\hline $\begin{array}{l}\text { 2. Is there a clear correlation between injection and } \\
\text { seismicity? }\end{array}$ & No \\
\hline 3. Are epicenters within $5 \mathrm{~km}$ of wells? & Yes \\
\hline 4. Do some earthquakes occur at or near injection depths? & Yes \\
\hline $\begin{array}{l}\text { 5. Are there known geologic structures that may channel } \\
\text { flow to sites of earthquakes? }\end{array}$ & Yes \\
\hline $\begin{array}{l}\text { 6. Are changes in fluid pressures at well bottoms } \\
\text { sufficient to encourage seismicity? }\end{array}$ & Unknown \\
\hline $\begin{array}{l}\text { 7. Are changes in fluid pressures at hypocentral distances } \\
\text { sufficient to encourage seismicity? }\end{array}$ & Unknown \\
\hline
\end{tabular}

estimates led to source radii from 39 to $563 \mathrm{~m}$. Stress drop is inversely proportional to the cube of corner frequency. Average stress drop estimates for the events $(P, S V$, and $S H$ combined) ranged from 5.5 to 128 bars, with the average for all estimates being 43.4 bars. Stress drops around 30 bars are common for small intraplate earthquakes (Kanamori and Anderson, 1975). These values all confirm the moderate size of the earthquakes $\left(M_{\mathrm{w}} \leq 2.9\right)$.

\section{Implications}

There were no felt earthquakes in Cleburne until the event on 2 June 2009 that was detected and located by the USGS. Wastewater injection began in 2005 at the northern well and in 2007 at the southern well (Fig. 2) well before the initiation of felt earthquakes. Although wastewater disposal may be linked to the Cleburne earthquakes, there has been no evidence that hydrofracturing, drilling, or natural gas production played any role in the events based on event timing, size distribution, and kinematics. Microearthquakes caused by hydrofracture occur only around the well while it is being fracked and are very rarely large enough to be felt. Wastewater injection, on the other hand, has triggered felt earthquakes in other areas (Evans, 1966; Davis and Pennington, 1989; Seeber et al., 2004; Horton, 2012). The Cleburne earthquakes were located within 1-3 km of injection wellsnot near other types of production activity. Additionally, there was no historical seismicity in the region prior to the onset of the DFW earthquakes (Frohlich et al., 2011) on 31 October 2008; these earthquakes are also located close to an injection well.

Davis and Frohlich (1993) proposed seven criteria to help assess whether fluid injection may have caused earthquake activity (Table 3). Answers for the Cleburne sequence are "yes" to four of the seven questions based on our analysis. Answers to two of the additional three questions cannot yet be determined. The Cleburne events did appear to be the first known earthquakes of this character in the region
(Question 1). Question 2 (Is there a clear correlation between injection and seismicity?) was answered "no" because injection started in 2005 and 2007, yet no felt earthquakes occurred until 2009. One of the injectors was shut-in in July 2009, yet felt events continued for months. Injection at the well closer to the earthquake locations continued in 2010 with increased yet modest fluid volumes, but no more events were felt. Questions 3 and 4 were answered "yes" because the events did occur within $5 \mathrm{~km}$ of an injection well and at or near their injection intervals. Question 5 was answered "yes" based on the observation that the wells are injecting into the Ellenburger limestone, which is known to be karsted so could facilitate fluid flow and distribution. The lack of fluid pressure data available to this study precluded answers to the remaining two questions. Such data might help resolve the relationship between the seismicity and the fluid disposal.

Zoback (2012) made a series of recommendations to reduce the probability of triggering seismicity when injecting into the subsurface. First, he suggests avoiding injection into faults. Injection wells are often reclaimed vertical wells that may have been drilled near a fault serving as a trap for hydrocarbons and as such may not be suitable for injection. Faults oriented with the ambient stress field are more likely to have triggered earthquakes. The Cleburne events are located near two injectors and their locations provide evidence that there is a nearby subsurface fault. The actual depth and extent is estimated from the earthquake locations and subsequent kinematic source analysis. Subsurface imagery might help further resolve near-surface faults.

The second recommendation is to minimize pore pressure changes at depth. In the case of the Cleburne disposal wells, injection occurs into the karsted Ellenburger limestone, where one would expect adequate fluid flow to prevent excessive pressure buildup. A detailed reservoir analysis would help quantify these effects. It is interesting to note that the injector with the largest volumes by over a factor of 3 was nearly $3.2 \mathrm{~km}$ away from the earthquake activity. The felt earthquakes started a number of years after the initiation of the injector and between 6 and 8 months after the injection volumes were nearly doubled. Additionally, the earthquake sequence decreased significantly six months after this injector was shut-in while the closer injector continued to operate but with significantly smaller volumes of fluids. Bottom hole injection pressures would help assess any relationship that might exist between the injected fluids and the earthquakes.

Third, Zoback proposes increasing the number of seismic monitoring arrays in order to map faults that might cause earthquakes. In the case of Cleburne, the seismic stations were added within two weeks of the first felt earthquake and provided documentation of the subsequent sequence. These stations were able to refine the event locations and better constrain the source depth. Additionally, the local stations provided the ability to estimate faulting parameters that were found to be consistent with not only the regional stress field, but also the known orientation of faults in the region. 
The fourth recommendation is that industry-wide protocols are needed to identify when to cut back injection once seismicity has occurred. Finally, Zoback recommends the obvious: stop injecting and abandon the well if the seismicity persists or if a fault capable of producing damaging earthquakes becomes apparent. One of the two injectors in this area was shut-in following the initiation of observed seismicity. This injector had the largest volumes in the region despite being farther from the estimated locations of the earthquakes. The seismicity decreased significantly about six months after this injector was shut-in. The second injector continued to operate but with lower volumes after the seismicity decreased.

The Cleburne earthquakes occurred close to two injection wells that were active at the onset of the sequence and in an area with no historical seismicity. The depth estimates of the events overlap with the injection intervals of the two wells. If the events were induced, fluid injection likely accommodated multiple episodes of small slip on a favorably oriented fault. The event locations in space and time, the characterization of the orientation of faulting, as well as the kinematic source estimates are all consistent with small earthquakes occurring along a buried fault with an orientation that corresponds to the current state of stress in the region. The spatial proximity of these events to two injector wells makes it difficult to rule out some causative effect. The delay time between the initiation of injection and the first felt report is difficult to assess without seismic monitoring records prior to June 2009. Additional subsurface information specific to this location similar to that recommended in the recent report by Zoback might provide a basis for further assessing the relationship between these earthquakes and nearby waste water injection wells. The events in this sequence were small but demonstrate the sensitivity of people to earthquakes in regions that have not historically experienced them.

\section{Data and Resources}

All data originated in this study.

\section{Acknowledgments}

The authors would like to thank George Marti, the Cleburne Municipal Airport, and Double B. Boat and R. V. for providing monitoring sites, and Chester Nolan, the former Cleburne City Manager, who coordinated the deployment sites at the Cleburne fire stations. The authors thank SMU for providing funding for this unique study. The authors especially would like to thank the reviewers, Cezar Trifu, and an anonymous reviewer, whose feedback proved instrumental in improving the quality of the paper.

The instruments used in the field program were provided by the PASSCAL facility of the Incorporated Research Institutions for Seismology (IRIS) through the PASSCAL Instrument Center at New Mexico Tech. Data collected during this experiment will be available through the IRIS Data Management Center. The facilities of the IRIS Consortium are supported by the National Science Foundation under Cooperative Agreement EAR-0552316 and by the Department of Energy National Nuclear Security Administration. Coauthor C. F. acknowledges partial support for this research from the USGS, Department of the Interior, under USGS award number G13AP00023, and from Research Partnership to Secure Energy for America (RPSEA) subcon- tract number 11122-27. The views and conclusions contained in this document are those of the authors and should not be interpreted as representing the official policies, either expressed or implied, of the U.S. Government.

\section{References}

Aki, K. (1965). Maximum likelihood estimate of $b$ in the formula $\log (N)=a-b M$ and its confidence limits, Bull. Earthq. Res. Inst. Tokyo Univ. 43, 237-239.

Boore, D. M., and J. Boatwright (1984). Average body-wave radiation coefficients, Bull. Seismol. Soc. Am. 74, 1615-1621.

Brune, J. N. (1970). Tectonic stress and the spectra of seismic shear waves from earthquakes, J. Geophys. Res. 26, 4997-5009.

Davis, S. D., and C. Frohlich (1993). Did (or will) fluid injection cause earthquakes? Criteria for a rational assessment, Seismol. Res. Lett. 64, 207-224.

Davis, S. D., and W. D. Pennington (1989). Induced seismic deformation in the Cogdell Oil Field of West Texas, Bull. Seismol. Soc. Am. 79, $1477-1494$

Evans, D. M. (1966). The Denver area earthquakes and the Rocky Mountain Arsenal disposal well, Mt. Geol. 3, no. 1, 23-36.

Ewing, T. (1990). Tectonic Map of Texas, University of Texas Bureau of Economic Geology, Austin, Texas.

Fehler, M., and W. S. Phillips (1991). Simultaneous inversion for $Q$ and source parameters of microearthquakes accompanying hydraulic fracturing in granitic rock, Bull. Seismol. Soc. Am. 81, 553-575.

Frohlich, C. (1993). Users Manual for TexFlex-0.5: The Texas Flexible, Practical Program for Locating Seismic Events, Univ. Texas Inst. Geophys. Tech. Rept. No. 128, Austin, Texas, 64 pp.

Frohlich, C. (2012). Two-year survey comparing earthquake activity and injection-well locations in the Barnett Shale, Texas, Proc. Natl. Acad. Sci. 109, 13,934-13,938, doi: 10.1073/pnas.1207728109.

Frohlich, C., C. Hayward, B. Stump, and E. Potter (2011). The Dallas-Fort Worth earthquake sequence: October 2008 through May 2009, Bull. Seismol. Soc. Am. 101, 327-340.

Geotechnical Corporation (1964). Deep-hole site report, Trigg No. 1, Dallas County, Texas, Geotechnical Corporation Tech. Rept. 64-100.

Goforth, T. T., and J. L. Bonner (1995). Characteristics of $R g$ waves recorded from quarry blasts in central Texas, Bull. Seismol. Soc. Am. 85, 12321235 .

Havskov, J., and L. Ottemoller (2010). Routine Data Processing in Earthquake Seismology, Springer, Dordrecht, the Netherlands, 347 pp.

Herrmann, R. B., S. Park, and C. Wang (1981). The Denver earthquakes of 1967-1968, Bull. Seismol. Soc. Am. 71, 731-745.

Horton, S. (2012). Disposal of hydrofracking waste fluid by injection into subsurface aquifers triggers earthquake swarm in central Arkansas with potential for damaging earthquake, Seismol. Res. Lett. 83, no. 2, 250-260.

Howe, A. M. (2012). Analysis of the Cleburne earthquake sequence from June 2009 to June 2010, Masters Abstracts International, Southern Methodist University, Vol. 51-01, Proquest/UMI, http://gradworks .umi.com/15/14/1514750.html (last accessed September 2013).

Kanamori, H., and D. L. Anderson (1975). Theoretical basis of some empirical relations in seismology, Bull. Seismol. Soc. Am. 65, 1073-1095.

Kisslinger, C. (1980). Evaluation of $S$ to $P$ amplitude ratios for determining focal mechanisms from regional network observations, Bull. Seismol. Soc. Am. 70, 999-1014.

Martineau, D. F. (2007). History of the Newark East field and the Barnett Shale as a gas reservoir, AAPG Bull. 91, 399-403.

Railroad Commission of Texas, form W-2, API 42-251-30299, 2007a, http:// rrcsearch.neubus.com/esd-rrc/index.php?_module_=esd\&_action= viewimage \&id=zaUpgf $7 \mathrm{hNaQ}$.\&oversized $=0$ \&profile $=$ OGP (last accessed September 2013).

Railroad Commission of Texas, form W-2, API 42-251-31266, 2007b, http:// rrcsearch.neubus.com/esd-rrc/index.php?_module_=esd\&action= viewimage $\& i d=V h Q S 78 O R E-M . \& o v e r s i z e d=0 \&$ profile=OGP (last accessed September 2013). 
Railroad Commission of Texas, Newark, East, (Barnett Shale) Statistics, 2009.

Seeber, L., J. G. Armbuster, and W. Y. Kim (2004). A fluid-injectiontriggered earthquake sequence in Ashtabula, Ohio: Implications for seismogenesis in stable continental regions, Bull. Seismol. Soc. Am. 94, 76-87.

Shi, Y., and B. A. Bolt (1982): The standard error of the magnitudefrequency $b$-value, Bull. Seismol. Soc. Am. 72,1677-1687.

Snoke, J. A. (2009). FOCMEC: FOCal MEChanisms Determinations. Manual., http://www.iris.edu/software/downloads/processing/ (last accessed February 2012).

Sullivan, E. C., K. L. Marfurt, A. Lacazette, and M. Ammerman (2006) Application of new seismic attributes to collapse chimneys in the Fort Worth Basin, Geophysics 71, B111-B119.

Tingay, M. R. P., B. Muller, J. Reinecker, and O. Heidbach (2006). State and origin of the present-day stress field in sedimentary basins: New results from the World Stress Map Project, in Proc. of the 41st US Symposium on Rock Mechanics: 50 Years of Rock Mechanics: Landmarks and Future Challenges, Golden, Colorado, 14 pp., CD-ROM ARMA/ USRM506-1049.

Trifu, C-I., D. Angus, and V. Shumila (2000). A fast evaluation of the seismic moment tensor for induced seismicity, Bull. Seismol. Soc. Am. 90, 1521-1527.

Urbancic, T. I., C. I. Trifu, R. A. Mercer, A. J. Feustel, and J. A. G. Alexander (1996). Automatic time-domain calculation of source parameters for the analysis of induced seismicity, Bull. Seismol. Soc. Am. 86, 1627-1633.

Zoback, M. (2012). Managing the seismic risk posed by wastewater disposal, Earth 57, no. 4, 38-43.

Southern Methodist University

Huffington Department of Earth Sciences

PO Box 750395

Dallas, Texas 75275-0395

ahowemail@gmail.com

bstump@smu.edu

hayward@smu.edu

(A.H.J., B.S., C.H.)

University of Texas as Austin

Institute for Geophysics, Jackson School of Geoscience

10100 Burnet Road (R2200)

Austin, Texas 78758-4445

cliff@utig.ig.utexas.edu

(C.F.)

Manuscript received 14 November 2012;

Published Online 8 October 2013 